\title{
Wnt signaling through T-cell factor phosphorylation
}

\author{
Sergei Y Sokol ${ }^{1}$ \\ ${ }^{I}$ Department of Developmental and Regenerative Biology, Mount Sinai School of Medicine, New York, NY 10029, USA
}

Embryonic signaling pathways often lead to a switch from default repression to transcriptional activation of target genes. A major consequence of Wnt signaling is stabilization of $\beta$-catenin, which associates with T-cell factors (TCFs) and 'converts' them from repressors into transcriptional activators. The molecular mechanisms responsible for this conversion remain poorly understood. Several studies have reported on the regulation of TCF by phosphorylation, yet its physiological significance has been unclear: in some cases it appears to promote target gene activation, in others Wnt-dependent transcription is inhibited. This review focuses on recent progress in the understanding of contextdependent post-translational regulation of TCF function by Wnt signaling.

Keywords: TCF; Wnt; phosphorylation; $\beta$-catenin; Homeodomain-interacting protein kinase; Nemo-like kinase Cell Research (2011) 21:1002-1012. doi:10.1038/cr.2011.86; published online 24 May 2011

\section{Introduction}

Wnt pathways play essential roles in cell fate determination, cell polarity and cell proliferation during embryonic development. The known branches of the Wnt signaling pathway involve the canonical, $\beta$-catenindependent pathway $[1,2]$, the planar cell polarity pathway, whose core players include Frizzled, Dishevelled, Van Gogh/Strabismus, Flamingo and Prickle [3, 4], and the less-studied $\mathrm{Ca}^{2+} /$ protein kinase $\mathrm{C}$ pathway $[5,6]$. In conjunction with Frizzled cell surface receptors [7, 8], LRP5/6 receptors are responsible for Wnt1- and Wnt3amediated signaling $[5,9]$, whereas ROR and RYK have been proposed to modulate cellular responses to Wnt5a [10-16]. Thus, the selectivity of the pathway for a specific branch appears to be determined by the specific Wnt ligands involved, the available Wnt receptors and coreceptors, and relative ligand-receptor affinities. Despite this apparent simplicity, the outcome of signaling is complex, because multiple pathways can be activated in parallel but to different degrees, depending on cell context.

\section{The Wnt/ $\beta$-catenin pathway}

Since the original observation that the level of Armadillo, the fly $\beta$-catenin homologue, is controlled by Wnt

Correspondence: Sergei Sokol

Tel: +1-212-241-1757; Fax: +1-212-860-9279

E-mail: sergei.sokol@mssm.edu signaling [17], much work for the past 20 years has been focused on $\beta$-catenin, a multifunctional protein, with essential roles in cell adhesion and target gene regulation [18-20]. Antisense depletion of $\beta$-catenin in Xenopus embryos [21] and its genetic knockouts in mice [22, 23] demonstrated a critical role for $\beta$-catenin in body axis specification and Wnt signaling. According to the consensus view, a key regulatory point in the signal transduction is the regulation of $\beta$-catenin. In the absence of a Wnt ligand, $\beta$-catenin undergoes proteosome-dependent degradation; Wnt stimulation inhibits this degradation, allowing $\beta$-catenin to enter the nucleus, associate with T-cell factor (TCF) proteins and activate target gene expression $[1,5]$. Besides $\beta$-catenin stabilization, additional factors are likely to further contribute to $\beta$-catenin nuclear entry. Although TCF proteins play major roles in transcriptional activation and repression, the signaling mechanisms involved have remained poorly understood. Nevertheless, the strategic downstream position of TCFs in the signaling cascade, due to their direct interactions with many protein cofactors and target DNA sequences, predicts another nodal point for Wnt pathway regulation.

\section{The TCF family and their cofactors}

There is a single TCF gene in Drosophila (pangolin, dTCF) [24, 25] and in Caenorhabditis elegans (POP1) [26], whereas there are four distinct TCF genes in vertebrates. TCF proteins associate with transcriptional repressors, such as Groucho/Grg/TLE (transducin-like 
enhancer of split) [27, 28], CtBP [29, 30], Kaiso [31-33], histone deacetylases (HDACs) and other factors, which maintain chromatin in the transcriptionally inactive state $[34,35]$ and could mediate TCF-dependent transcriptional repression [28, 36-39]. The current model is that TCF proteins inhibit target genes when bound to Groucho/TLE corepressors, while association with $\beta$-catenin blocks these interactions and converts TCFs into transcriptional activators [1, 37, 40-43].

One of the better-studied models is the regulation of POP-1, the C. elegans TCF homologue, during the binary fate decision of the EMS progenitor cell. Asymmetric division of the EMS progenitor generates the MS (mesodermal) cell and the E (endodermal) cell [44-46]. Both cells produce endoderm in pop- 1 mutants, indicating that POP-1 normally suppresses endodermal fate in the MS cell lineage [26]. In the E cell, levels of nuclear POP-1 are reduced by MOM-2/Wnt signaling [47-49]. This POP-1 asymmetry requires LIT-1, a protein kinase that regulates asymmetric cell divisions [50] and promotes the nuclear export of POP-1 [49, 51, 52]. Paradoxically, the small amount of POP-1 that remains in the E-cell nucleus is required, together with SYS-1, a distant member of the $\beta$-catenin family $[53,54]$, for Wnt-dependent activation of endoderm-specific end-1 and end-3 target genes [44, 45, 47, 55-57]. POP-1 also functions as a transcriptional activator in $\mathrm{T}$ neuroblasts and somatic gonadal precursors, in which POP-1 and SYS-1 directly activate the ceh-22/tinman gene $[47,53,54,58]$. These observations emphasize the dual function of POP-1 in transcriptional control.

The complex roles of POP-1 in transcription are modulated by two of the four specialized members of the $\beta$-catenin family: SYS-1, WRM-1, BAR-1 and HMP-2 $[59,60]$. Whereas SYS-1 cooperates with POP-1 in target activation, WRM-1 serves to remove POP-1 from the nucleus of the $\mathrm{E}$ cell, thereby relieving transcriptional repression $[51,52]$. BAR- 1 is the canonical $\beta$-catenin that is regulated by glycogen synthase kinase (GSK)3-dependent phosphorylation and degradation, whereas HMP-2 largely functions in cell adhesion. These two proteins do not appear to be involved in POP-1 regulation $[47,61]$.

In contrast to the single $T C F$ genes that perform both positive and negative roles in transcriptional regulation in C. elegans and Drosophila [24, 36, 43], the four conserved vertebrate $T C F$ homologues: $T C F 1, L E F 1$, $T C F 3$ and TCF4, appear to be more specialized, as well as partly redundant $[1,62]$. LEF1-/- mouse embryos lack teeth, mammary glands, and hair and are deficient in neural crest development [63], whereas double knockouts of $T C F$ genes display more severe phenotypes [64-
66]. Similarly, in Xenopus and zebrafish embryos, TCF proteins play diverse roles in dorsoventral patterning, CNS, neural crest and muscle development [67-72]. The observed differences in loss-of-function phenotypes can be attributed, at least in part, to the spatially and temporally restricted $T C F$ expression patterns and the existence of multiple spliced forms $[62,73]$. It is also possible that individual vertebrate TCFs have functions that are independent of their role in Wnt-regulated transcriptional regulation. TCF proteins are usually unable to functionally substitute for each other, arguing against the simple view that they function by allowing $\beta$-catenin binding to target promoters. Since $T C F$ gene knockout and knockdown phenotypes do not mimic $\beta$-catenin and Wnt lossof-function defects in a straightforward manner, it is important to understand the causes for these discrepancies and develop a mechanistic model that is consistent with available data.

\section{Regulation by phosphorylation}

Accumulating evidence suggests that TCF proteins are phosphorylated in response to Wnt signals and this phosphorylation might be important for determining signaling outcome. In C. elegans, the phosphorylation of POP-1 is critical for POP-1 asymmetry and was proposed to promote signal-induced endodermal fate, although its physiological significance with respect to Mom-2/Wnt signaling remains to be fully established [48, 51, 52, 74-76]. In mammalian cells, Wnt1 can promote the phosphorylation of TCF4 [77], but there are conflicting reports regarding the ability of Wnt5a to stimulate LEF-1 and TCF4 phosphorylation [77, 78]. In Xenopus embryos and mammalian cells, we find that TCF3, TCF4 and LEF1 are phosphorylated in response to Wnt8 and Wnt3a, both in vitro and in vivo $[79,80]$ (Figure 1 ). TCF3 constructs with mutated phosphorylation sites function as constitutive transcriptional repressors, indicating the essential role of this phosphorylation for signaling [79]. Thus, TCF phosphorylation appears to be a conserved mechanism operating in parallel with $\beta$-catenin stabilization to control Wnt target gene activation [80].

Several protein kinases have been reported to phosphorylate TCF proteins (Figure 2). Casein kinase $1 \varepsilon$ (CK1 1 ) can phosphorylate TCF3 and enhance TCF- $\beta$ catenin complex formation, whereas GSK3 $\beta$ phosphorylates TCF3 to inhibit $\beta$-catenin-TCF3 interactions [81]. By contrast, casein kinase $1 \delta(\mathrm{CK} 1 \delta)$-dependent phosphorylation has been reported to negatively influence LEF-1/ $\beta$-catenin complex formation [82]. Phosphorylation by casein kinase 2 (CK2) promotes LEF-1 binding to chromatin [83], but reduces TCF-4 association with 


\section{Two branches of the 'canonical' Wnt pathway}

\section{Vertebrates}

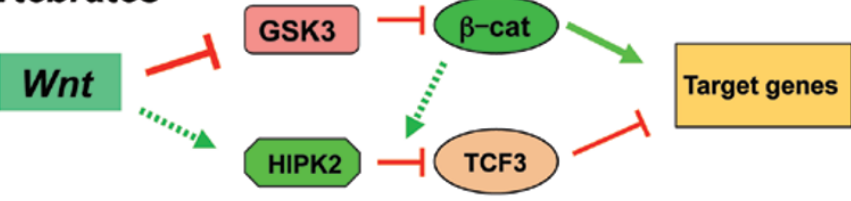

\section{C. elegans}

Wnt

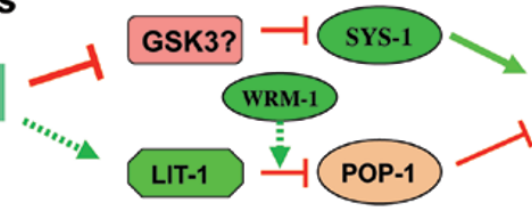

Target genes

Figure 1 Two conserved branches of the canonical Wnt pathway. In vertebrates, Wnt signaling acts to prevent $\beta$-catenin degradation and promote its ability to activate transcription. SYS-1 is a functional substitute of $\beta$-catenin in the early $C$. elegans embryo. The other conserved signaling branch is to inhibit TCF3 (vertebrate embryos) or POP-1 (C. elegans) repressive activity by phosphorylation.

plakoglobin $/ \gamma$-catenin [84]. In C. elegans, LIT-1 phosphorylates POP-1 to promote its nuclear export $[49,51$, 52]. While NLK, the mammalian homologue of LIT-1, can phosphorylate TCF proteins to inhibit TCF4 binding to DNA and reduce Wnt signaling in mammalian cells $[76,78]$, it was also reported to promote Wnt signaling in zebrafish embryos [85]. Since NLK can be activated by oppositely acting Wnt1 and Wnt5 $[77,86]$, there is a need to explain its context-dependent functions.
Another family of protein kinases implicated in Wnt signaling are homeodomain-interacting protein kinases (HIPK1-4) $[87,88]$. In the mouse, HIPK2 is expressed in multiple embryonic tissues, including the brain, heart, kidney and muscle [89]. HIPK2 has been implicated in transcriptional regulation, cell growth and apoptosis [9092], presumably by activating p53 [93-95] and/or c-Jun N-terminal kinase [96]. Embryos lacking both HIPK1 and HIPK2 genes display severe exencephaly with ante-

\section{Protein kinases involved in TCF phosphorylation}

\begin{tabular}{|c|c|c|c|c|}
\hline & HIPK2 & NLK/LIT-1 & CK1/2 & GSK3 \\
\hline $\begin{array}{l}\text { Role in } \\
\text { embryonic } \\
\text { patterning: }\end{array}$ & $\begin{array}{l}\text { Promotes } \\
\text { ventroposterior } \\
\text { development }\end{array}$ & $\begin{array}{l}\text { Promotes } \\
\text { ventroposterior } \\
\text { development }\end{array}$ & Various & $\begin{array}{l}\text { Promotes } \\
\text { anterior } \\
\text { development }\end{array}$ \\
\hline $\begin{array}{l}\text { Phosphorylation } \\
\text { substrates }\end{array}$ & TCF3 & POP-1, TCF4, LEF-1 & TCF3, TCF4,LEF-1 & TCF3 \\
\hline $\begin{array}{l}\text { Phosphorylation } \\
\text { sites }\end{array}$ & P2, P3, P4 & $\mathrm{P} 3$, Ser118/127 in POP-1 & Multiple & Unknown \\
\hline $\begin{array}{l}\text { Upstream } \\
\text { regulators }\end{array}$ & Wnt3, Wnt8, TAK1 & Wnt1, Wnt5, TAK1 & Multiple & Wnt3, Wnt1 \\
\hline
\end{tabular}

Figure 2 HIPK2 and NLK/LIT-1 in Wnt signaling. The comparison of several properties of HIPK2 and NLK indicates that these kinases might function in the same signaling pathway during anteroposterior axis specification in vertebrate embryos. Casein kinases 1 and 2 as well as GSK3 are also involved in TCF phosphorylation (see text). 
rior neural tissue overgrowth and die between e9.5 and e12.5 [97]. HIPK2-mediated phosphorylation promotes proteasome-dependent degradation of CtBP $[98,99]$ and attenuates the repressive activity of Groucho [98]. The HIPK2/NLK complex was found to phosphorylate and degrade c-Myb in response to Wnt1 [100]. Other studies have reported both positive and negative effects of HIPK on Wnt/ $\beta$-catenin signaling in mouse embryo fibroblasts [101, 102], Drosophila and Xenopus embryos [103, 104], but the underlying mechanisms remain to be fully elucidated. Linking HIPK2 more directly to TCF regulation, a recent study has shown that HIPK2 acts to antagonize TCF3 activity, thereby promoting ventroposterior development in Xenopus [79]. HIPK2 is required for Wnt8dependent TCF3 phosphorylation, which results in the removal of TCF3 from target promoters culminating in target gene activation [79].

Since both NLK and HIPK2 can phosphorylate vertebrate TCF proteins and trigger their removal from promoter DNA, the question arises whether these two protein kinases function in the same or distinct molecular pathways (Figure 2). Interestingly, both HIPK2 and NLK have been found to control anteroposterior axis specification in Xenopus and zebrafish embryos [79, 85]. The two NLK phosphorylation sites on LEF-1 [78] correspond to a subset of the Wnt8-dependent, HIPK2 phosphorylation sites within TCF3, while two additional clusters of phosphorylation sites appear to be specific for HIPK2 [79]. Both NLK and HIPK2 cooperate in Wnt-1-dependent degradation of c-Myb in CV-1 fibroblasts [100], and both kinases can be stimulated by TGF $\beta$-activated kinase (TAK1) [75, 76, 100, 105, 106]. Interestingly, HIPK2 has been shown to phosphorylate and activate NLK in vitro [100]. Together, these observations identify HIPK2 and NLK as regulators of TCF activity, although it remains unclear whether they function in the same developmental process and act sequentially or in parallel.

\section{A new common branch of the Wnt pathway?}

The Wnt/HIPK2-dependent TCF3 phosphorylation [79] illustrates the importance of TCF post-translational modification in vivo. While this pathway is similar to the Wnt/NLK/POP-1 pathway proposed for C. elegans [45, 47] (Figure 1), the upstream regulators of both pathways are largely unknown. A priori, HIPK2 may be constitutively required for this phosphorylation, or it may be activated in response to a Wnt signal, as has been proposed for c-Myb regulation [100]. The latter possibility seems more likely since overexpressed $\beta$-catenin was unable on its own to upregulate TCF3 phosphorylation [79], suggesting that Wnt signals regulate both $\beta$-catenin stability and HIPK2 activity. Interestingly, the 'canonical' LRP5/6 receptor and the inhibition of GSK3 have been both implicated in TCF3 phosphorylation [80]. Further research is needed to identify other intracellular intermediates involved.

Mammalian TAK1 and its worm homologue MOM4 have been reported to function upstream of NLK/LIT1 [75-77, 100, 106]. Moreover, HIPK2 was proposed to act downstream of TAK1 in c-Myb degradation [100]. Although the direct activation of HIPK2 by TAK has not been demonstrated, it seems reasonable to hypothesize that TAK 1 is one of the upstream components of the Wnt/HIPK2/TCF3 pathway. It is worth noting that, like HIPK2, TAK1 has been reported to play a role in Xenopus ventroposterior development, although this function was attributed to its effects on BMP rather than Wnt signaling [107]. Since both BMP and Wnt signaling are involved in setting up ventroposterior gene expression in vertebrate embryos [108-110], TAK1 might be a molecular component of the Wnt signaling machinery that activates HIPK2 and NLK.

A commonly accepted function of $\beta$-catenin is coactivation of TCF-dependent transcription. However, $\beta$-catenin appears to play a distinct novel role in Wnt/ HIPK2-dependent TCF3 phosphorylation. Whereas overexpression of $\beta$-catenin does not cause TCF3 phosphorylation, its depletion inhibits TCF3 phosphorylation [79]. Moreover, TCF3 harboring point mutations that prevent $\beta$-catenin binding is no longer phosphorylated in response to Wnt signals, suggesting that $\beta$-catenin functions as a scaffold required for HIPK2 phosphorylation of TCF3 [79] (Figure 1). This is reminiscent of the role of WRM-1 in promoting LIT-1-mediated POP-1 phosphorylation [52]. On the other hand, WRM-1 only weakly associates with POP-1, and $\beta$-catenin does not seem to activate HIPK2 in vivo, at least as judged by the lack of TCF3 phosphorylation upon overexpression of $\beta$-catenin alone [79].

The identification of signaling components that are involved in TCF phosphorylation in response to $\mathrm{Wnt}$ signals will assist in our understanding of Wnt signaling processes coordinating morphogenesis and cell fate determination during embryonic development.

\section{Mechanisms of target gene regulation}

Canonical Wnt signaling has been thought to activate target genes by increasing the level of $\beta$-catenin, thereby favoring the formation of $\beta$-catenin/TCF complexes, and their binding to target promoters. Many proteins that bind to the $\beta$-catenin/TCF complex and regulate target gene transcription have been described but will not be 


\section{Mechanisms of target gene regulation by TCF phosphorylation}

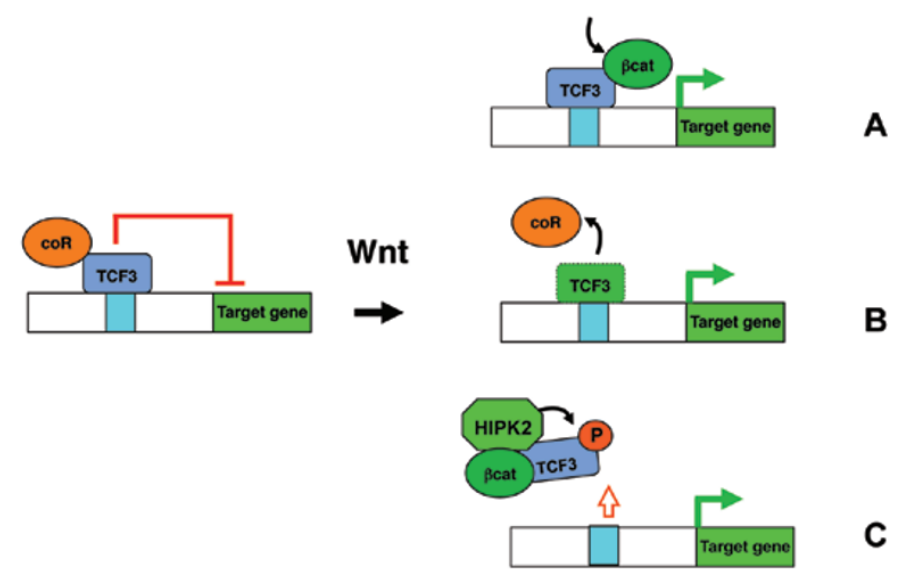

Figure 3 Mechanisms of target gene regulation by Wnt-dependent TCF phosphorylation. (A) Wnt signaling results in the binding of a transcriptional coactivator ( $\beta$-catenin) to TCF3, stimulating a target gene. (B) Co-repressor (coR, e.g., Groucho) removal converts TCF3 from a repressor into an activator, resulting in target gene activation. (C) Target gene is activated when the complex of $\beta$-catenin, TCF3 and HIPK2 forms, leading to decreased affinity of TCF3 to promoter DNA.

discussed here due to space limitations [42, 62, 111-114]. In the simplest scenario, the function of $\beta$-catenin might be to provide a transcriptional activation domain to the TCF protein (which binds DNA via its high mobility group (HMG) domain) [40, 115] (Figure 3). In another model, upon its binding to TCF proteins, $\beta$-catenin converts them into transcriptional activators by outcompeting transcriptional corepressors, such as Groucho, CtBP or HDACs $[36,37,39,43,116]$. Since both models presume the association of TCF with DNA, a phosphorylation event (such as that mediated by NLK or HIPK2) that causes the dissociation of TCF from the promoter would be predicted to inhibit both types of TCF-dependent gene activation $[76,77,79,86]$.

In the third case, phosphorylation of a repressor-type TCF, such as TCF3, and its subsequent displacement from promoter DNA would result in target gene activation. This mechanism is likely to operate for Vent gene activation in Xenopus and zebrafish early embryos. Vent2/Vent/Vox genes [117-121] are expressed in the ventrolateral region and are induced by Wnt8 $[85,122]$. Vent genes encode homeodomain transcription factors that antagonize dorsal genes to establish the ventroposterior embryonic domain $[120,121,123]$. Wnt8 activates a Vent 2 reporter through the unique proximal TCFbinding site [79]. Unexpectedly, a Vent2 reporter with the mutated TCF-binding site displays higher activity than the wild-type promoter and the in vivo depletion of Tcf3 leads to wild-type reporter activation [79]. Finally, TCF3 phosphorylation by HIPK 2 or in response to a Wnt signal leads to the dissociation of TCF3 from the Vent promoter in vivo [79]. These observations establish an essential role for HIPK2-dependent phosphorylation in Vent 2 regulation by alleviation of TCF3-mediated repression.

Since TCF3 is involved in the repression of a large number of genes in early embryos and stem cells [124128], other gene targets are likely to be controlled by this mechanism. The $C d x$ (caudal) and the Meis group genes, like Vent genes, are regulated by Wnt signaling during anteroposterior patterning [129-131] and contain multiple TCF-binding sites in their DNA regulatory elements [132-134]. Like Vent genes, these genes are also controlled by TCF3-mediated repression [79]. Moreover, other characterized $\beta$-catenin responsive genes, including Siamois, have been found to contain negative regulatory TCF-binding sites, implying similar regulation $[135,136]$. Thus, the HIPK2 phosphorylation-dependent mechanism of TCF3 displacement is likely to be of broad significance in gene activation.

Similar to HIPK2-mediated TCF3 phosphorylation, NLK is known to reduce TCF4 and LEF-1 in vitro affinities for promoter DNA [76] and LIT-1-dependent POP-1 phosphorylation results in POP-1 nuclear export [51]. The sites of POP-1 phosphorylation by LIT-1 are distinct from $\mathrm{P} 2 / 3 / 4$ sites of TCF 3 , but they are located in the same general area of the protein, upstream of the DNAbinding domain [51], arguing for the same mechanism of transcriptional derepression. How might HIPK2- or NLK-mediated phosphorylation trigger TCF protein dissociation from the promoter? Since the phosphorylation 


\section{Context-dependent function of HIPK2}

\section{A. TCF3, repressor type}

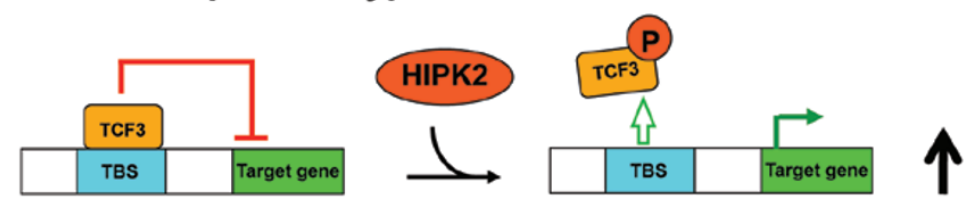

B. LEF1, activator type
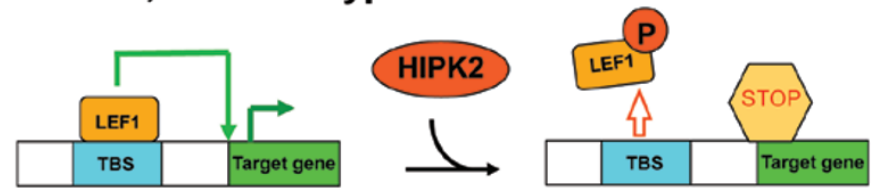

Figure 4 Context-dependent function of HIPK2 in Wnt signaling. A positive or negative role of HIPK2 in Wnt signaling depends on the availability and type of TCF proteins that are present in the responding cell. HIPK2 would inhibit the pathway upon phosphorylation of an activator type TCF, such as LEF1, but would activate it upon phosphorylation of a repressor, such as TCF3.

is outside of the DNA-binding HMG domain, the most likely possibility is a conformational change in the protein leading to allosteric regulation. The proposed phosphorylation sites are located in the region of TCF3 that is responsible for Groucho binding (sometimes called the context-dependent region) $[62,78]$. Therefore, the alternative explanation is that the phosphorylation modulates the interaction of TCF3 with Groucho/TLE, HDACs or other cofactors [35, 38, 111, 113, 114, 137, 138], which may be necessary for optimal chromatin binding. Among other potential TCF3 regulators is Dishevelled, which shuttles to the nucleus [139], interacts with HIPK1 [104], and stabilizes $\beta$-catenin/TCF interactions [140]. Of interest, TCF1 has been reported to undergo nuclear export [141], but this is unlikely to be regulated by the same phosphorylation event, since the relevant $\mathrm{P} 2 / 3 / 4$ sites are not present in TCF1. Thus, HIPK and NLK are likely to function together with other components of transcription regulatory machinery to regulate Wnt target genes.

Conservation of HIPK2 phosphorylation sites in different TCF proteins, including TCF3, TCF4 and LEF1 $[79,80]$, provides a possible explanation for the contextdependent function of HIPK in Wnt signaling. Based on the upregulation of the Wnt target gene cyclin D1 in HIPK2-/- mouse embryo fibroblasts and studies in Xenopus, HIPK homologs have been proposed to suppress Wnt target gene expression [101, 102, 104]. In contrast, Xenopus HIPK2 and Drosophila HIPK were shown to stimulate Wnt target genes [79, 103]. In a vertebrate study, HIPK2 did not show a significant effect on $\beta$-catenin [79], as reported for Drosophila embryos [103], indicating significant divergence of HIPK molecular substrates in fly and vertebrate embryos. These conflicting observations are resolved in a model, in which HIPK2 plays a positive or negative signaling role, depending on the functional properties of TCF proteins that are present in the embryonic tissue. Specifically, HIPK2 would inhibit the pathway when an activator type TCF, such as LEF1, is phosphorylated, but would activate it when phosphorylating the repressive form of TCF (TCF3) (Figure 4).

Whereas different TCF proteins are known to play diverse roles in early development [70], the mechanistic explanation for Wnt pathway regulation at the level of TCF has been missing. The same explanation for context dependence may be applicable to NLK, which has also been reported to function in Wnt signaling in both positive and negative manners $[85,86]$. One apparent contradiction relates to the similarity of lit-1 and pop- 1 mutant phenotypes in somatic gonadal precursors in $C$. elegans that implies synergistic rather than antagonistic functions [142]. This synergy could be misleading, as both the excess of POP-1 in lit-1 mutants and the lack of POP-1 in pop-1 mutants would be inhibitory to ceh-22 expression. Additional experiments are necessary to find out whether the phosphorylation of additional molecular substrates by LIT-1 is required for the regulation of POP-1-dependent transcription in this system.

\section{Conclusions}

Recent studies point to the significance of TCF phos- 
phorylation, as a distinct downstream Wnt signaling target regulated in parallel with $\beta$-catenin. Wnt-dependent activation of HIPK2 and NLK, that phosphorylate TCF, is predicted to lead to context-dependent regulation of target genes, determined by the availability and type of TCF protein(s) present. While other molecular components of this pathway remain largely to be discovered, existing knowledge is consistent with the prediction that Wnt-dependent TCF phosphorylation is a general and conserved point of regulation from worms to mammals.

\section{Acknowledgment}

The author thanks M Klymkowsky, R Korswagen and P McCrea for comments on the manuscript and H Hikasa for numerous discussions. I apologize to those authors whose work has not been cited here due to limited space. The work in the author's laboratory is supported by NIH grants.

\section{References}

1 Clevers H. Wnt/beta-catenin signaling in development and disease. Cell 2006; 127:469-480.

2 Logan CY, Nusse R. The Wnt signaling pathway in development and disease. Annu Rev Cell Dev Biol 2004; 20:781-810.

3 Klein TJ, Mlodzik M. Planar cell polarization: an emerging model points in the right direction. Annu Rev Cell Dev Biol 2005; 21:155-176.

4 Vladar EK, Antic D, Axelrod JD. Planar cell polarity signaling: the developing cell's compass. Cold Spring Harb Perspect Biol 2009; 1:a002964.

5 MacDonald BT, Tamai K, He X. Wnt/beta-catenin signaling: components, mechanisms, and diseases. Dev Cell 2009; 17:9-26.

6 Angers S, Moon RT. Proximal events in Wnt signal transduction. Nat Rev Mol Cell Biol 2009; 10:468-477.

7 Bhanot P, Brink M, Samos CH, et al. A new member of the frizzled family from Drosophila functions as a Wingless receptor. Nature 1996; 382:225-230.

8 Mikels AJ, Nusse R. Wnts as ligands: processing, secretion and reception. Oncogene 2006; 25:7461-7468.

9 He X, Semenov M, Tamai K, Zeng X. LDL receptor-related proteins 5 and 6 in Wnt/beta-catenin signaling: arrows point the way. Development 2004; 131:1663-1677.

10 Lin S, Baye LM, Westfall TA, Slusarski DC. Wnt5b-Ryk pathway provides directional signals to regulate gastrulation movement. J Cell Biol 2010; 190:263-278.

11 Mikels AJ, Nusse R. Purified Wnt5a protein activates or inhibits beta-catenin-TCF signaling depending on receptor context. PLoS Biol 2006; 4:e115.

12 Nishita M, Yoo SK, Nomachi A, et al. Filopodia formation mediated by receptor tyrosine kinase Ror2 is required for Wnt5a-induced cell migration. J Cell Biol 2006; 175:555562 .

13 Hikasa H, Shibata M, Hiratani I, Taira M. The Xenopus receptor tyrosine kinase Xror2 modulates morphogenetic movements of the axial mesoderm and neuroectoderm via
Wnt signaling. Development 2002; 129:5227-5239.

14 Schambony A, Wedlich D. Wnt-5A/Ror2 regulate expression of XPAPC through an alternative noncanonical signaling pathway. Dev Cell 2007; 12:779-792.

15 Nishita M, Itsukushima S, Nomachi A, et al. Ror2/Frizzled complex mediates Wnt5a-induced AP-1 activation by regulating Dishevelled polymerization. Mol Cell Biol 2010; 30:3610-3619.

16 Lu W, Yamamoto V, Ortega B, Baltimore D. Mammalian Ryk is a Wnt coreceptor required for stimulation of neurite outgrowth. Cell 2004; 119:97-108.

17 Riggleman B, Schedl P, Wieschaus E. Spatial expression of the Drosophila segment polarity gene armadillo is posttranscriptionally regulated by wingless. Cell 1990; 63:549-560.

18 Nelson WJ, Nusse R. Convergence of Wnt, beta-catenin, and cadherin pathways. Science 2004; 303:1483-1487.

19 Gumbiner BM. Regulation of cadherin-mediated adhesion in morphogenesis. Nat Rev Mol Cell Biol 2005; 6:622-634.

20 Grigoryan T, Wend P, Klaus A, Birchmeier W. Deciphering the function of canonical Wnt signals in development and disease: conditional loss- and gain-of-function mutations of beta-catenin in mice. Genes Dev 2008; 22:2308-2341.

21 Heasman J, Crawford A, Goldstone K, et al. Overexpression of cadherins and underexpression of beta-catenin inhibit dorsal mesoderm induction in early Xenopus embryos. Cell 1994; 79:791-803.

22 Haegel H, Larue L, Ohsugi M, et al. Lack of beta-catenin affects mouse development at gastrulation. Development 1995; 121:3529-3537.

23 Huelsken J, Vogel R, Brinkmann V, et al. Requirement for beta-catenin in anterior-posterior axis formation in mice. $J$ Cell Biol 2000; 148:567-578.

24 Brunner E, Peter O, Schweizer L, Basler K. pangolin encodes a Lef-1 homologue that acts downstream of Armadillo to transduce the Wingless signal in Drosophila. Nature 1997; 385:829-833.

25 Riese J, Yu X, Munnerlyn A, et al. LEF-1, a nuclear factor coordinating signaling inputs from wingless and decapentaplegic. Cell 1997; 88:777-787.

26 Lin R, Thompson S, Priess JR. pop-1 encodes an HMG box protein required for the specification of a mesoderm precursor in early C. elegans embryos. Cell 1995; 83:599-609.

27 Gasperowicz M, Otto F. Mammalian Groucho homologs: redundancy or specificity? J Cell Biochem 2005; 95:670-687.

28 Brantjes H, Roose J, van De Wetering M, Clevers H. All Tcf HMG box transcription factors interact with Groucho-related co-repressors. Nucleic Acids Res 2001; 29:1410-1419.

29 Valenta T, Lukas J, Korinek V. HMG box transcription factor TCF-4's interaction with CtBP1 controls the expression of the Wnt target Axin2/Conductin in human embryonic kidney cells. Nucleic Acids Res 2003; 31:2369-2380.

30 Brannon M, Brown JD, Bates R, Kimelman D, Moon RT. $\mathrm{XCtBP}$ is a XTcf-3 co-repressor with roles throughout Xenopus development. Development 1999; 126:3159-3170.

31 van Roy FM, McCrea PD. A role for Kaiso-p120ctn complexes in cancer? Nat Rev Cancer 2005; 5:956-964.

32 Ruzov A, Hackett JA, Prokhortchouk A, et al. The interaction of xKaiso with xTcf3: a revised model for integration of epigenetic and Wnt signalling pathways. Development 2009; 
136:723-727.

33 Park JI, Kim SW, Lyons JP, et al. Kaiso/p120-catenin and $\mathrm{TCF} /$ beta-catenin complexes coordinately regulate canonical Wnt gene targets. Dev Cell 2005; 8:843-854.

34 Chen G, Fernandez J, Mische S, Courey AJ. A functional interaction between the histone deacetylase $\operatorname{Rpd} 3$ and the corepressor groucho in Drosophila development. Genes Dev 1999; 13:2218-2230.

35 Calvo D, Victor M, Gay F, et al. A POP-1 repressor complex restricts inappropriate cell type-specific gene transcription during Caenorhabditis elegans embryogenesis. EMBO J 2001; 20:7197-7208.

36 Roose J, Molenaar M, Peterson J, et al. The Xenopus Wnt effector XTcf-3 interacts with Groucho-related transcriptional repressors. Nature 1998; 395:608-612.

37 Daniels DL, Weis WI. Beta-catenin directly displaces Groucho/TLE repressors from Tcf/Lef in Wnt-mediated transcription activation. Nat Struct Mol Biol 2005; 12:364-371.

38 Ye F, Chen Y, Hoang T, et al. HDAC1 and HDAC2 regulate oligodendrocyte differentiation by disrupting the betacatenin-TCF interaction. Nat Neurosci 2009; 12:829-838.

39 Song H, Goetze S, Bischof J, et al. Coop functions as a corepressor of Pangolin and antagonizes Wingless signaling. Genes Dev 2010; 24:881-886.

40 van de Wetering M, Cavallo R, Dooijes D, et al. Armadillo coactivates transcription driven by the product of the Drosophila segment polarity gene dTCF. Cell 1997; 88:789-799.

41 Behrens J, von Kries JP, Kuhl M, et al. Functional interaction of beta-catenin with the transcription factor LEF-1. Nature 1996; 382:638-642.

42 Barolo S, Posakony JW. Three habits of highly effective signaling pathways: principles of transcriptional control by developmental cell signaling. Genes Dev 2002; 16:1167-1181.

43 Cavallo RA, Cox RT, Moline MM, et al. Drosophila Tcf and Groucho interact to repress Wingless signalling activity. $\mathrm{Na}$ ture 1998; 395:604-608.

44 Maduro MF, Lin R, Rothman JH. Dynamics of a developmental switch: recursive intracellular and intranuclear redistribution of Caenorhabditis elegans POP-1 parallels Wntinhibited transcriptional repression. Dev Biol 2002; 248:128142.

45 Mizumoto K, Sawa H. Two betas or not two betas: regulation of asymmetric division by beta-catenin. Trends Cell Biol 2007; 17:465-473.

46 Goldstein B. Induction of gut in Caenorhabditis elegans embryos. Nature 1992; 357:255-257.

47 Phillips BT, Kimble J. A new look at TCF and beta-catenin through the lens of a divergent $C$. elegans Wnt pathway. Dev Cell 2009; 17:27-34.

48 Thorpe CJ, Schlesinger A, Carter JC, Bowerman B. Wnt signaling polarizes an early C. elegans blastomere to distinguish endoderm from mesoderm. Cell 1997; 90:695-705.

49 Rocheleau CE, Downs WD, Lin R, et al. Wnt signaling and an APC-related gene specify endoderm in early C. elegans embryos. Cell 1997; 90:707-716.

50 Kaletta T, Schnabel H, Schnabel R. Binary specification of the embryonic lineage in Caenorhabditis elegans. Nature 1997; 390:294-298.

51 Lo MC, Gay F, Odom R, Shi Y, Lin R. Phosphorylation by the beta-catenin/MAPK complex promotes 14-3-3-mediated nuclear export of TCF/POP-1 in signal-responsive cells in $C$. elegans. Cell 2004; 117:95-106.

52 Rocheleau CE, Yasuda J, Shin TH, et al. WRM-1 activates the LIT-1 protein kinase to transduce anterior/posterior polarity signals in C. elegans. Cell 1999; 97:717-726.

53 Lam N, Chesney MA, Kimble J. Wnt signaling and CEH-22/ tinman/Nkx2.5 specify a stem cell niche in C. elegans. Curr Biol 2006; 16:287-295.

54 Kidd AR, III, Miskowski JA, Siegfried KR, Sawa H, Kimble J. A beta-catenin identified by functional rather than sequence criteria and its role in Wnt/MAPK signaling. Cell 2005; 121:761-772.

55 Shetty P, Lo MC, Robertson SM, Lin R. C. elegans TCF protein, POP-1, converts from repressor to activator as a result of Wnt-induced lowering of nuclear levels. Dev Biol 2005; 285:584-592.

56 Huang S, Shetty P, Robertson SM, Lin R. Binary cell fate specification during $C$. elegans embryogenesis driven by reiterated reciprocal asymmetry of TCF POP-1 and its coactivator beta-catenin SYS-1. Development 2007; 134:2685-2695.

57 Maduro MF, Kasmir JJ, Zhu J, Rothman JH. The Wnt effector POP-1 and the PAL-1/Caudal homeoprotein collaborate with SKN-1 to activate $C$. elegans endoderm development. Dev Biol 2005; 285:510-523.

58 Siegfried KR, Kidd AR 3rd, Chesney MA, Kimble J. The sys- 1 and sys- 3 genes cooperate with Wnt signaling to establish the proximal-distal axis of the Caenorhabditis elegans gonad. Genetics 2004; 166:171-186.

59 Korswagen HC. Canonical and non-canonical Wnt signaling pathways in Caenorhabditis elegans: variations on a common signaling theme. Bioessays 2002; 24:801-810.

60 Eisenmann DM, Maloof JN, Simske JS, Kenyon C, Kim SK. The beta-catenin homolog BAR-1 and LET-60 Ras coordinately regulate the Hox gene lin-39 during Caenorhabditis elegans vulval development. Development 1998; 125:36673680 .

61 Korswagen HC, Herman MA, Clevers HC. Distinct betacatenins mediate adhesion and signalling functions in $C$. elegans. Nature 2000; 406:527-532.

62 Arce L, Yokoyama NN, Waterman ML. Diversity of LEF/ TCF action in development and disease. Oncogene 2006; 25:7492-7504.

63 van Genderen C, Okamura RM, Farinas I, et al. Development of several organs that require inductive epithelial-mesenchymal interactions is impaired in LEF-1-deficient mice. Genes Dev 1994; 8:2691-2703.

64 Galceran J, Farinas I, Depew MJ, Clevers H, Grosschedl R. Wnt3a-/--like phenotype and limb deficiency in Lef1(-/-) Tcf1(-/-) mice. Genes Dev 1999; 13:709-717.

65 Gregorieff A, Grosschedl R, Clevers H. Hindgut defects and transformation of the gastro-intestinal tract in $\mathrm{Tcf} 4(-/-) /$ Tcf1(-/-) embryos. EMBO J 2004; 23:1825-1833.

66 Nguyen H, Merrill BJ, Polak L, et al. Tcf3 and Tcf4 are essential for long-term homeostasis of skin epithelia. Nat Genet 2009; 41:1068-1075.

67 Gradl D, Konig A, Wedlich D. Functional diversity of Xenopus lymphoid enhancer factor/T-cell factor transcription factors relies on combinations of activating and repressing 
elements. J Biol Chem 2002; 277:14159-14171.

68 Standley HJ, Destree O, Kofron M, Wylie C, Heasman J. Maternal XTcfl and XTcf4 have distinct roles in regulating Wnt target genes. Dev Biol 2006; 289:318-328.

69 Liu F, van den Broek O, Destree O, Hoppler S. Distinct roles for Xenopus Tcf/Lef genes in mediating specific responses to Wnt/beta-catenin signalling in mesoderm development. Development 2005; 132:5375-5385.

70 Roel G, Hamilton FS, Gent Y, et al. Lef-1 and Tcf-3 transcription factors mediate tissue-specific Wnt signaling during Xenopus development. Curr Biol 2002; 12:1941-1945.

71 Bonner J, Gribble SL, Veien ES, et al. Proliferation and patterning are mediated independently in the dorsal spinal cord downstream of canonical Wnt signaling. Dev Biol 2008; 313:398-407.

72 Dorsky RI, Itoh M, Moon RT, Chitnis A. Two tcf3 genes cooperate to pattern the zebrafish brain. Development 2003; 130:1937-1947.

73 Atcha FA, Syed A, Wu B, et al. A unique DNA binding domain converts T-cell factors into strong Wnt effectors. Mol Cell Biol 2007; 27:8352-8363.

74 Lin R, Hill RJ, Priess JR. POP-1 and anterior-posterior fate decisions in C. elegans embryos. Cell 1998; 92:229-239.

75 Meneghini MD, Ishitani T, Carter JC, et al. MAP kinase and Wnt pathways converge to downregulate an HMG-domain repressor in Caenorhabditis elegans. Nature 1999; 399:793797.

76 Ishitani T, Ninomiya-Tsuji J, Nagai S, et al. The TAK1-NLKMAPK-related pathway antagonizes signalling between betacatenin and transcription factor TCF. Nature 1999; 399:798802.

77 Smit L, Baas A, Kuipers J, et al. Wnt activates the Tak1/ Nemo-like kinase pathway. J Biol Chem 2004; 279:1723217240 .

78 Ishitani T, Ninomiya-Tsuji J, Matsumoto K. Regulation of lymphoid enhancer factor 1/T-cell factor by mitogenactivated protein kinase-related Nemo-like kinase-dependent phosphorylation in Wnt/beta-catenin signaling. Mol Cell Biol 2003; 23:1379-1389.

79 Hikasa H, Ezan J, Itoh K, et al. Regulation of TCF3 by Wntdependent phosphorylation during vertebrate axis specification. Dev Cell 2010; 19:521-532.

80 Hikasa H, Sokol SY. Phosphorylation of TCF proteins by homeodomain-interacting protein kinase 2. J Biol Chem 2011; 286:12093-12100.

81 Lee E, Salic A, Kirschner MW. Physiological regulation of [beta]-catenin stability by Tcf3 and CK1epsilon. J Cell Biol 2001; 154:983-993.

82 Hammerlein A, Weiske J, Huber O. A second protein kinase CK1-mediated step negatively regulates Wnt signalling by disrupting the lymphocyte enhancer factor-1/beta-catenin complex. Cell Mol Life Sci 2005; 62:606-618.

83 Wang S, Jones KA. CK2 controls the recruitment of Wnt regulators to target genes in vivo. Curr Biol 2006; 16:22392244.

84 Miravet S, Piedra J, Miro F, et al. The transcriptional factor Tcf-4 contains different binding sites for beta-catenin and plakoglobin. J Biol Chem 2002; 277:1884-1891.

85 Thorpe CJ, Moon RT. nemo-like kinase is an essential co-ac- tivator of Wnt signaling during early zebrafish development. Development 2004; 131:2899-2909.

86 Ishitani T, Kishida S, Hyodo-Miura J, et al. The TAK1-NLK mitogen-activated protein kinase cascade functions in the Wnt-5a/Ca(2+) pathway to antagonize Wnt/beta-catenin signaling. Mol Cell Biol 2003; 23:131-139.

87 Kim YH, Choi CY, Lee SJ, Conti MA, Kim Y. Homeodomain-interacting protein kinases, a novel family of co-repressors for homeodomain transcription factors. J Biol Chem 1998; 273:25875-25879.

88 Rinaldo C, Prodosmo A, Siepi F, Soddu S. HIPK2: a multitalented partner for transcription factors in DNA damage response and development. Biochem Cell Biol 2007; 85:411418.

89 Pierantoni GM, Bulfone A, Pentimalli F, et al. The homeodomain-interacting protein kinase 2 gene is expressed late in embryogenesis and preferentially in retina, muscle, and neural tissues. Biochem Biophys Res Commun 2002; 290:942947.

90 Kondo S, Lu Y, Debbas M, et al. Characterization of cells and gene-targeted mice deficient for the p53-binding kinase homeodomain-interacting protein kinase 1 (HIPK1). Proc Natl Acad Sci USA 2003; 100:5431-5436.

91 Doxakis E, Huang EJ, Davies AM. Homeodomain-interacting protein kinase-2 regulates apoptosis in developing sensory and sympathetic neurons. Curr Biol 2004; 14:17611765 .

92 Calzado MA, Renner F, Roscic A, Schmitz ML. HIPK2: a versatile switchboard regulating the transcription machinery and cell death. Cell Cycle 2007; 6:139-143.

93 D'Orazi G, Cecchinelli B, Bruno T, et al. Homeodomaininteracting protein kinase-2 phosphorylates p53 at Ser 46 and mediates apoptosis. Nat Cell Biol 2002; 4:11-19.

94 Hofmann TG, Moller A, Sirma H, et al. Regulation of p53 activity by its interaction with homeodomain-interacting protein kinase-2. Nat Cell Biol 2002; 4:1-10.

95 Dauth I, Kruger J, Hofmann TG. Homeodomain-interacting protein kinase 2 is the ionizing radiation-activated p53 serine 46 kinase and is regulated by ATM. Cancer Res 2007; 67:2274-2279.

96 Hofmann TG, Stollberg N, Schmitz ML, Will H. HIPK2 regulates transforming growth factor-beta-induced c-Jun NH(2)terminal kinase activation and apoptosis in human hepatoma cells. Cancer Res 2003; 63:8271-8277.

97 Isono K, Nemoto K, Li Y, et al. Overlapping roles for homeodomain-interacting protein kinases hipk1 and hipk2 in the mediation of cell growth in response to morphogenetic and genotoxic signals. Mol Cell Biol 2006; 26:2758-2771.

98 Choi CY, Kim YH, Kim YO, et al. Phosphorylation by the DHIPK2 protein kinase modulates the corepressor activity of Groucho. J Biol Chem 2005; 280:21427-21436.

99 Zhang Q, Yoshimatsu Y, Hildebrand J, Frisch SM, Goodman $\mathrm{RH}$. Homeodomain interacting protein kinase 2 promotes apoptosis by downregulating the transcriptional corepressor CtBP. Cell 2003; 115:177-186.

100 Kanei-Ishii C, Ninomiya-Tsuji J, Tanikawa J, et al. Wnt-1 signal induces phosphorylation and degradation of $\mathrm{c}-\mathrm{Myb}$ protein via TAK1, HIPK2, and NLK. Genes Dev 2004; 18:816-829. 
101 Wei G, Ku S, Ma GK, et al. HIPK2 represses beta-cateninmediated transcription, epidermal stem cell expansion, and skin tumorigenesis. Proc Natl Acad Sci USA 2007; 104:13040-13045.

102 Kim EA, Kim JE, Sung KS, et al. Homeodomain-interacting protein kinase 2 (HIPK2) targets beta-catenin for phosphorylation and proteasomal degradation. Biochem Biophys Res Commun 2010; 394:966-971.

103 Lee W, Swarup S, Chen J, Ishitani T, Verheyen EM. Homeodomain-interacting protein kinases (Hipks) promote Wnt/ Wg signaling through stabilization of beta-catenin/Arm and stimulation of target gene expression. Development 2009; 136:241-251.

104 Louie SH, Yang XY, Conrad WH, et al. Modulation of the beta-catenin signaling pathway by the dishevelled-associated protein Hipk1. PLoS ONE 2009; 4:e4310.

105 Yamaguchi K, Shirakabe K, Shibuya H, et al. Identification of a member of the MAPKKK family as a potential mediator of TGF-beta signal transduction. Science 1995; 270:20082011.

106 Shin TH, Yasuda J, Rocheleau CE, et al. MOM-4, a MAP kinase kinase kinase-related protein, activates WRM-1/LIT-1 kinase to transduce anterior/posterior polarity signals in $C$. elegans. Mol Cell 1999; 4:275-280.

107 Shibuya H, Iwata H, Masuyama N, et al. Role of TAK1 and TAB1 in BMP signaling in early Xenopus development. EMBO J 1998; 17:1019-1028.

108 Hoppler S, Moon RT. BMP-2/-4 and Wnt-8 cooperatively pattern the Xenopus mesoderm. Mech Dev 1998; 71:119-129.

109 De Robertis EM, Kuroda H. Dorsal-ventral patterning and neural induction in Xenopus embryos. Annu Rev Cell Dev Biol 2004; 20:285-308.

110 Schier AF, Talbot WS. Molecular genetics of axis formation in zebrafish. Annu Rev Genet 2005; 39:561-613.

111 Cadigan KM. Wnt/beta-catenin signaling: turning the switch. Dev Cell 2008; 14:322-323.

112 Mosimann C, Hausmann G, Basler K. Beta-catenin hits chromatin: regulation of Wnt target gene activation. Nat Rev Mol Cell Biol 2009; 10:276-286.

113 Sierra J, Yoshida T, Joazeiro CA, Jones KA. The APC tumor suppressor counteracts beta-catenin activation and $\mathrm{H} 3 \mathrm{~K} 4$ methylation at Wnt target genes. Genes Dev 2006; 20:586600.

114 Li J, Wang CY. TBL1-TBLR1 and beta-catenin recruit each other to Wnt target-gene promoter for transcription activation and oncogenesis. Nat Cell Biol 2008; 10:160-169.

115 Vleminckx K, Kemler R, Hecht A. The C-terminal transactivation domain of beta-catenin is necessary and sufficient for signaling by the LEF-1/beta-catenin complex in Xenopus laevis. Mech Dev 1999; 81:65-74.

116 Levanon D, Goldstein RE, Bernstein Y, et al. Transcriptional repression by AML1 and LEF-1 is mediated by the TLE/Groucho corepressors. Proc Natl Acad Sci USA 1998; 95:11590-11595.

117 Gawantka V, Delius H, Hirschfeld K, Blumenstock C, Niehrs C. Antagonizing the Spemann organizer: role of the homeobox gene Xvent-1. EMBO J 1995; 14:6268-6279.

118 Schmidt JE, von Dassow G, Kimelman D. Regulation of dorsal-ventral patterning: the ventralizing effects of the novel
Xenopus homeobox gene Vox. Development 1996; 122:17111721.

119 Ladher R, Mohun TJ, Smith JC, Snape AM. Xom: a Xenopus homeobox gene that mediates the early effects of BMP-4. Development 1996; 122:2385-2394.

120 Imai Y, Gates MA, Melby AE, et al. The homeobox genes vox and vent are redundant repressors of dorsal fates in zebrafish. Development 2001; 128:2407-2420.

121 Onichtchouk D, Gawantka V, Dosch R, et al. The Xvent-2 homeobox gene is part of the BMP-4 signalling pathway controlling [correction of controling] dorsoventral patterning of Xenopus mesoderm. Development 1996; 122:3045-3053.

122 Ramel MC, Lekven AC. Repression of the vertebrate organizer by Wnt8 is mediated by Vent and Vox. Development 2004; 131:3991-4000.

123 Sander V, Reversade B, De Robertis EM. The opposing homeobox genes Goosecoid and Vent1/2 self-regulate Xenopus patterning. EMBO J 2007; 26:2955-2965.

124 Houston DW, Kofron M, Resnik E, et al. Repression of organizer genes in dorsal and ventral Xenopus cells mediated by maternal XTcf3. Development 2002; 129:4015-4025.

125 Cole MF, Johnstone SE, Newman JJ, Kagey MH, Young RA. Tcf3 is an integral component of the core regulatory circuitry of embryonic stem cells. Genes Dev 2008; 22:746-755.

126 Yi F, Pereira L, Merrill BJ. Tcf3 functions as a steady-state limiter of transcriptional programs of mouse embryonic stem cell self-renewal. Stem Cells 2008; 26:1951-1960.

127 Nguyen H, Rendl M, Fuchs E. Tcf3 governs stem cell features and represses cell fate determination in skin. Cell 2006; 127:171-183.

128 Tam WL, Lim CY, Han J, et al. Tcf3 regulates embryonic stem cell pluripotency and self-renewal by the transcriptional control of multiple lineage pathways. Stem Cells 2008; 26:2019-2031.

129 Elkouby YM, Elias S, Casey ES, et al. Mesodermal Wnt signaling organizes the neural plate via Meis3. Development 2010; 137:1531-1541.

130 Epstein M, Pillemer G, Yelin R, Yisraeli JK, Fainsod A. Patterning of the embryo along the anterior-posterior axis: the role of the caudal genes. Development 1997; 124:3805-3814.

131 Keenan ID, Sharrard RM, Isaacs HV. FGF signal transduction and the regulation of $\mathrm{Cdx}$ gene expression. Dev Biol 2006; 299:478-488.

132 Haremaki T, Tanaka Y, Hongo I, Yuge M, Okamoto H. Integration of multiple signal transducing pathways on Fgf response elements of the Xenopus caudal homologue Xcad3. Development 2003; 130:4907-4917.

133 Pilon N, Oh K, Sylvestre JR, et al. Cdx4 is a direct target of the canonical Wnt pathway. Dev Biol 2006; 289:55-63.

134 Shimizu T, Bae YK, Muraoka O, Hibi M. Interaction of Wnt and caudal-related genes in zebrafish posterior body formation. Dev Biol 2005; 279:125-141.

135 Fan MJ, Gruning W, Walz G, Sokol SY. Wnt signaling and transcriptional control of Siamois in Xenopus embryos. Proc Natl Acad Sci USA 1998; 95:5626-5631.

136 Brannon M, Gomperts M, Sumoy L, Moon RT, Kimelman D. A beta-catenin/XTcf-3 complex binds to the siamois promoter to regulate dorsal axis specification in Xenopus. Genes Dev 1997; 11:2359-2370. 
137 Billin AN, Thirlwell H, Ayer DE. Beta-catenin-histone deacetylase interactions regulate the transition of LEF1 from a transcriptional repressor to an activator. Mol Cell Biol 2000; 20:6882-6890.

138 Arce L, Pate KT, Waterman ML. Groucho binds two conserved regions of LEF-1 for HDAC-dependent repression. BMC Cancer 2009; 9:159.

139 Itoh K, Brott BK, Bae GU, Ratcliffe MJ, Sokol SY. Nuclear localization is required for Dishevelled function in Wnt/betacatenin signaling. J Biol 2005; 4:3.
140 Gan XQ, Wang JY, Xi Y, et al. Nuclear Dvl, c-Jun, betacatenin, and TCF form a complex leading to stabilization of beta-catenin-TCF interaction. J Cell Biol 2008; 180:10871100.

141 Najdi R, Syed A, Arce L, et al. A Wnt kinase network alters nuclear localization of TCF-1 in colon cancer. Oncogene 2009; 28:4133-4146.

142 Siegfried KR, Kimble J. POP-1 controls axis formation during early gonadogenesis in C. elegans. Development 2002; 129:443-453. 